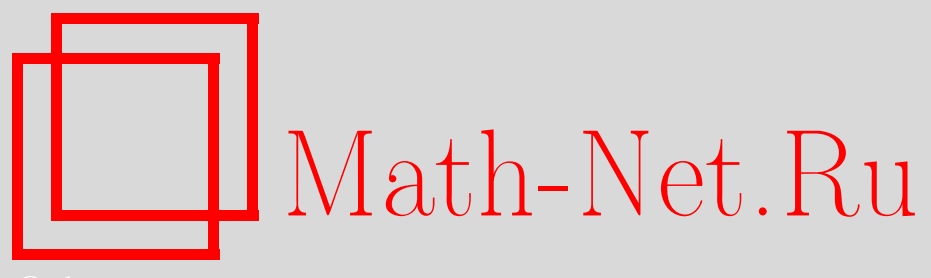

И. Я. Арефьева, В. Е. Захаров, В. В. Козлов, И. М. Кричевер, В. П. Маслов, С. П. Новиков, А. М. Поляков, Н. Ю. Решетихин, М. А. Семенов-Тян-Шанский, Е. К. Склянин, Ф. А. Смирнов, Л. А. Тахтаджян, С. Л. Шаташвили, Людвиг Дмитриевич Фаддеев (некролог), УМН, 2017, том 72, выпуск 6, 191-196

DOI: https://doi.org/10.4213/rm9798

Использование Общероссийского математического портала Math-Net.Ru подразумевает, что вы прочитали и согласны с пользовательским соглашением http://www.mathnet.ru/rus/agreement

Параметры загрузки:

IP : 35.173 .137 .237

26 апреля 2023 г., 16:22:26

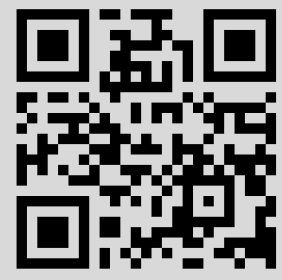




\section{Людвиг Дмитриевич Фаддеев}

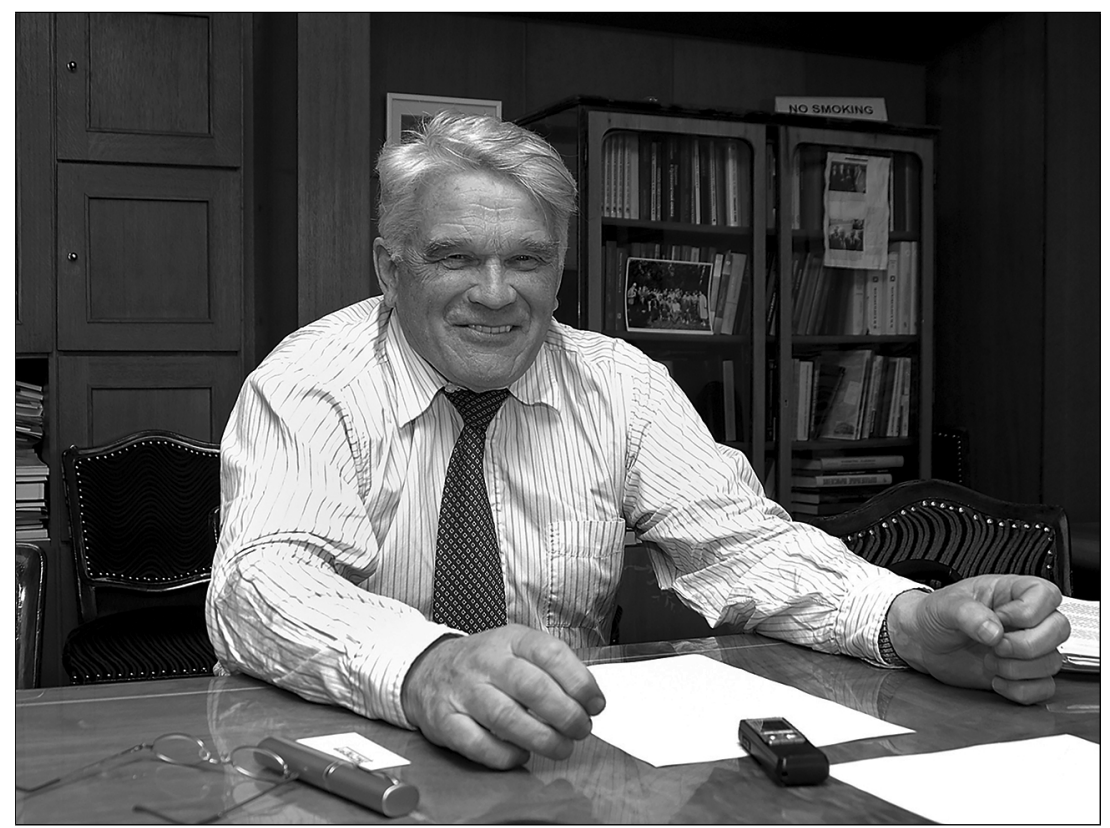

В феврале 2017 г. скончался один из крупнейших математиков и физиков-теоретиков современности академик Людвиг Дмитриевич Фаддеев. Уход Фаддеева - тяжелая утрата для российской и мировой науки. Его труды в значительной мере сформировали современную математическую физику, развитию которой он посвятил всю свою жизнь. Многие его результаты стали классическими - они вошли в золотой фонд чистой математики и вместе с тем сыграли определяющую роль в развитии важнейших разделов теоретической физики. Ему принадлежит и огромный вклад в преодоление накопившегося за десятилетия разрыва между математикой и физикой, в формирование нескольких поколений российских и мировых теоретиков. На протяжении более 60 лет научная жизнь Людвига Дмитриевича была связана с Ленинградским (затем Петербургским) отделением Математического института им. В.А. Стеклова, где он прошел путь от аспиранта до заведующего созданной им самим лабораторией и директора института. Созданием лаборатории математических проблем физики, в которой работали выросшие под его руководством ученики, Людвиг Дмитриевич гордился не меньше, чем своими чисто научными результатами. В 1976 г. в возрасте 42 лет Л. Д. Фаддеев был избран действительным членом Академии наук СССР, а с 1992 г. и до конца жизни возглавлял Отделение математики РАН, позже Отделение математических наук.

DOI: https://doi.org/10.4213/rm9798 
Жизнь Людвига Дмитриевича была и счастливой, и вместе с тем драматической. Многое из того, о чем он мечтал еще в юности, ему удалось реализовать. Вместе с тем фундаментальная наука, которой он посвятил всю свою жизнь, оказывалась в разные периоды его жизни не нужна властям, вымаривавшим науку на "голодном пайке", а затем демонстративно навязавшим унизительную "реформу" Академии наук, вопреки мнению научного сообщества. Об этих событиях Людвиг Дмитриевич говорил с большой горечью. В разных формах его противостояние некомпетентной власти продолжалось долгие годы - в 1990-е это была борьба за сохранение организованного им Международного математического института им. Леонарда Эйлера. Стрессовые ситуации, связанные с этим институтом, стоили Людвигу Дмитриевичу инфаркта.

Л. Д. Фаддеев родился 23 марта 1934 г. в Ленинграде в семье замечательных математиков Дмитрия Константиновича и Веры Николаевны Фаддеевых. Д. К. Фаддеев был одним из ведущих советских алгебраистов, основателем ленинградской школы современной алгебры. В.Н. Фаддеева на протяжении многих лет возглавляла созданную ею лабораторию вычислительных методов ЛОМИ. Дмитрий Константинович был также замечательным пианистом, вместе с Верой Николаевной они мечтали о музыкальной карьере сына. Хотя эти планы не осуществились из-за войны, Людвиг Дмитриевич навсегда сохранил глубокий интерес к музыке. Поступая в университет, он выбрал не математический факультет (деканом которого был в то время его отец), а физический. Как он сам отмечал впоследствии, в этом решении сказался его нонконформизм и желание проложить в жизни и в науке независимый путь. Его главным учителем на кафедре математики физического факультета ЛГУ стала Ольга Александровна Ладыженская. Она не только читала ряд обязательных курсов, но и организовала студенческий семинар, в котором Людвиг Дмитриевич был одним из главных докладчиков. Кандидатская диссертация, дающая полное решение обратной задачи рассеяния для одномерного оператора Шрёдингера на прямой, была подготовлена Л. Д. Фаддеевым под руководством О. А. Ладыженской в ЛОМИ, с которым оказалась связанной вся его дальнейшая научная жизнь. Он навсегда сохранил чувство глубокой признательности Ольге Александровне. Ее портрет оставался на рабочем столе в кабинете Людвига Дмитриевича в ПОМИ до последних дней его жизни.

Со студенческих лет Л. Д. Фаддеева привлекала математическая красота и сложность квантовой теории поля. Однако в середине 1950-х годов после блестящих успехов, связанных с построением квантовой электродинамики, квантовая теория поля столкнулась с серьезными трудностями, надолго став “немодной"; выход из этих трудностей искали, с одной стороны, в попытках построения амплитуды рассеяния исходя из ее постулируемых аналитических свойств, а с другой стороны - в развитии абстрактного аксиоматического подхода. Ни один из этих подходов не казался Л. Д. Фаддееву привлекательным - он считал, что правильные модели, свободные от трудностей, подорвавших веру в самое существование квантовой теории поля, должны обладать прежде всего математической (в частности, геометрической) красотой. Заниматься квантовой теорией поля в те годы можно было лишь в одиночку, вопреки мейнстриму. Чтобы обеспечить себе определенную базу, Л. Д. Фаддеев хотел прежде всего получить решение технически сложной задачи. Такой задачей стала квантово-механическая задача трех тел, в которой Л. Д. Фаддееву удалось получить решающее продвижение в начале 1960-х годов. Эта работа (ставшая темой его докторской диссертации) вызвала огромный интерес у теоретиков, занимающихся прикладными аспектами квантовой физики (теория атомных столкновений, теория ядра) и породила поистине необъятную литературу. Вместе с тем она представляла собой и значительное техническое достижение с точки зрения чистой математики: это был один из первых примеров исчерпывающего изучения дифференциального оператора со сложной структурой непрерывного спектра. Интересно, что одна из основных идей этой работы - перестройка интегральных уравнений теории рассеяния в так называемые уравнения Фаддеева, позволяющая контролировать вклад непрерывного спектра, - возникла у Людвига Дмитриевича под влиянием изучения модели Тирринга - 
простейшей (но уже далеко не тривиальной) модели квантовой теории поля. В следующем десятилетии та же модель Тирринга вновь сыграла важную роль в работах по квантовому методу обратной задачи. Работа по многочастичному рассеянию была активно продолжена учениками и коллегами Людвига Дмитриевича (В. С. Буслаев, О. А. Якубовский, С. П. Меркурьев), но сам он, завершив свою ставшую знаменитой монографию о квантовой задаче трех тел, решительно обратился к другой, еще более трудной области - квантовой теории поля.

Опыт работы с дифференциальными операторами со сложной структурой непрерывного спектра оказался полезен еще в одной задаче, которой Л. Д. Фаддеев занялся в середине 1960-х годов по инициативе И. М. Гельфанда, - теории автоморфных функций (для дискретных групп на некомпактной фундаментальной области конечной площади в плоскости Лобачевского). Л. Д. Фаддееву принадлежит первое полное неарифметическое доказательство теоремы разложения и (совместно с А.Б. Венковым и В.Л. Калининым) формулы следа Сельберга для некомпактных римановых поверхностей с конечной площадью. Вместе с Б. С. Павловым Людвиг Дмитриевич предложил и интересную нестационарную формулировку задачи рассеяния для автомофных функций, позволяющую интерпретировать нули дзета-функции Римана как квантово-механические резонансы.

В 1966 г. Л. Д. Фаддеев вместе с В. Н. Поповым получили решающее продвижение в построении квантовой теории поля Янга-Миллса. Значение этой работы в полной мере проявилось через несколько лет, когда теория Янга-Миллса стала основой теории электрослабых и сильных взаимодействий в теории элементарных частиц. Метод фейнмановских функциональных интегралов, использованный Фаддеевым и Поповым, вошел в рабочий аппарат новой теории. Как любил говорить Людвиг Дмитриевич, им удалось переиграть Фейнмана на его собственном поле.

Уже в первой статье Фаддеева и Попова отмечалось, что предложенный ими метод имеет весьма общий характер; в качестве другого приложения в ней были сформулированы правила квантования гравитационного поля. Намеченный авторами метод квантования гравитации был затем развит в нескольких публикациях. (Замечательно, что преобразование функционального интеграла к гамильтоновой форме позволило просто получить гамильтонову формулировку теории тяготения, что важно не только в квантовой, но и в классической теории, в частности при исследовании проблемы положительности энергии. В 1960-е годы Л. Д. Фаддеев получил в связи с проблемой положительности один из лучших в то время результатов; полностью задача была решена спустя 10 лет Ш.-Т. Яу и Р. Шёном, а затем более просто Ә. Виттеном.) K сожалению, возможности теории возмущений в квантовой гравитации сильно ограничены ее неперенормируемостью. Однако по мере того как идеи квантовой теории поля проникали во все новые области математики - в теорию представлений, а затем и в топологию, - универсальность и гибкость метода Фаддеева-Попова становились все более очевидными.

Работы по методу обратной задачи теории рассеяния были одной из важных тем исследований Л. Д. Фаддеева еще с конца 1950-х годов. В это время им получено обобщение результатов Гельфанда-Левитана-Марченко на случай уравнения Шрёдингера на всей оси, исследованы (вместе с В. С. Буслаевым) спектральные тождества следов для одномерного оператора Шрёдингера и, наконец, достигнуто решающее продвижение в трехмерной обратной задаче. Решение трехмерной обратной задачи для уравнения Шрёдингера Людвиг Дмитриевич считал своим лучшим аналитическим результатом. В конце 1960-х-начале 1970-х годов обратная задача теории рассеяния на прямой неожиданно оказалась связанной с захватывающими успехами в изучении нелинейных уравнений. Людвиг Дмитриевич с самого начала был одним из главных действующих лиц этого "героического периода", когда объем наших знаний об интегрируемых системах удваивался в промежуток между двумя конференциями. Уже его первая работа, посвященная этой тематике, немедленно стала классической - вместе с В.Е. Захаровым они показали, что уравнение Кортевега-де Фриза есть бесконечномерная гамильтонова система, интегрируемая по Лиувиллю. До этой работы не 
было известно ни одного нетривиального примера бесконечномерной интегрируемой системы (т. е. системы полевого типа). Значение работы В. Е. Захарова и Л. Д. Фаддеева было огромно - она означала, что бесконечномерные интегрируемые системы существуют и очень интересны и нетривиальны. Особенно интересным оказалось явное описание фазового пространства уравнения Кортевега-де Фриза в терминах "данных рассеяния" - в нем выделился вклад от знаменитых солитонных решений (уединенных волн), причем они вели себя как настоящие частицы. Произошла, как любил позже говорить В.Е. Захаров, смена парадигмы.

В теории интегрируемых нелинейных уравнений счастливым образом объединились все темы, которыми Л.Д. Фаддеев занимался в предшествующий период: обратная задача теории рассеяния, тождества следов, гамильтонова механика. При этом вклад Л. Д. Фаддеева в развитие метода обратной задачи определялся не только его чисто техническими достижениями, но не в меньшей степени его ролью учителя и организатора: именно в этот период сложилась возглавляемая Людвигом Дмитриевичем группа молодых сотрудников его лаборатории (в основном выпускников ленинградского физфака и матмеха, прошедших через его семинар в ЛОМИ), принадлежать к которой все считали для себя большой честью.

Интерес Л. Д. Фаддеева к изучению нелинейных уравнений с самого начала был связан не столько с их ролью полезных моделей в механике сплошных сред, сколько с возможными их приложениями в квантовой теории поля. В этом отношении исключительно важную роль сыграло уравнение sin-Гордона, лаксову пару и переменные “действие-угол" для которого Л.Д. Фаддеев построил вместе с Л. А. Тахтаджяном в 1973 г. Из этого результата следовала удивительная (пока еще квазиклассическая) картина спектра масс в квантовополевой релятивистской задаче: помимо частиц, соответствующих основному полю, в нем присутствовали еще солитоны и их связанные состояния; при этом солитоны несли нетривиальный заряд и их естественно было считать сильно взаимодействующими. Уравнение sin-Гордона впервые указало на роль частицеподобных классических решений и, более общим образом, на богатство правильно выбранных нелинейных моделей в квантовой теории поля. Идеологическое влияние этой работы на теоретическую физику 1970-1980-х годов было весьма значительным - из нее выросли солитонные решения в многомерных теориях (монополи 'т Хоофта-Полякова) и инстантонные решения в теории Янга-Миллса.

Параллельно с квазиклассическим квантованием солитонов в течение 1970-х годов шел поиск математического аппарата для точного решения двумерных квантовых моделей. Эти поиски привели к новому удачному синтезу - построению вместе с Е.К. Скляниным и Л.А. Тахтаджяном квантового метода обратной задачи, объединившего идеи классического метода обратной задачи с методами и результатами Р. Бакстера и Х. Бете. Удивительным образом в точном решении квантовополевой гамильтоновой модели нашли свое место и "бутстрапные" амплитуды рассеяния ( $S$-матрица А. Б. и Ал. Б. Замолодчиковых), изучавшиеся в 1960 -е годы в противовес гамильтоновым методам в теории поля. Одним из побочных продуктов нового развития стала теория квантовых групп, выросшая из изучения квантового уравнения Янга-Бакстера (впервые осознанного в качестве интересного алгебраического объекта именно в работах Л. Д. Фаддеева и его учеников) и превратившаяся, после работ В.Г. Дринфельда, в один из наиболее интересных сюжетов некоммутативной алгебры со времени открытия групп Ли. Вместе с Л. А. Тахтаджяном и Н. Ю. Решетихиным Людвиг Дмитриевич развил удобный и общий подход к квантованию групп и алгебр Ли, целиком основанный на использовании квантовых $R$-матриц. Этот подход привел к ряду важных продвижений - построению квантовых алгебр, отвечающих решеткам и произвольным графам, и квантовой деформации уравнений Книжника-Замолодчикова.

Квазиклассическая конструкция, связанная с $R$-матричным методом, а именно теория классических $r$-матриц, предложенная первоначально Е. К. Скляниным, позволила алгебраизировать классический метод обратной задачи и вместе с тем оказалась очень интересной с точки зрения симплектической и пуассоновой геометрии. 
Во всех этих результатах роль Л. Д. Фаддеева как активно работающего математика и учителя была исключительно велика.

В конце 1980-х-начале 1990-х годов наметился еще один синтез: между гамильтоновыми методами, характерными для квантового метода обратной задачи, и конформной теорией поля. Ковариантность по отношению к конечномерным квантовым группам, естественно возникающая в конформных теориях, была осознана как часть (бесконечномерной) скрытой симметрии, характерной для интегрируемых моделей. Работы Л. Д. Фаддеева этого периода способствовали прояснению скрытой квантовой симметрии и привели также к новым интересным решеточным моделям теории поля (в дискретном пространстве-времени), которые можно воспринимать и как нетривиальные примеры "некоммутативной геометрии" в духе А. Конна.

В 1980-е годы работы по квантовому методу обратной задачи несколько отодвинули на задний план в фаддеевской лаборатории "четырехмерную" физику, но и в этом направлении было получено несколько важных результатов, частично все еще остающихся "заделом" на будущее. Сюда относятся, прежде всего, работы Л. Д. Фаддеева и С. Л. Шаташвили по квантовополевым аномалиям и открытие интересного класса групповых когомологий и связанного с ним расширения трехмерной группы/алгебры калибровочных преобразований. Другим направлением, которое Л. Д. Фаддеев развивал в те годы, был поиск нетривиальных решений четырехмерных нелинейных уравнений, в которых роль топологического заряда играл инвариант Хопфа. Эти исследования были продолжены в 1990-е годы совместно с финским физиком А. Ниеми, подтвердившим с помощью численных методов существование устойчивых "заузленных" решений уравнений модифицированной модели Скирма, предложенной в работах Л. Д. Фаддеева.

Распад СССР и глубокий кризис, в который погрузилась страна, привел к коренным изменениям в жизни российской науки. В результате многие из сотрудников созданной Л. Д. Фаддеевым лаборатории стали работать в ведущих американских и европейских университетах. Из-за стрессовых ситуаций 1990-х годов безвременно ушли из жизни несколько его ближайших сотрудников: А. Г. Изергин, А. П. Осколков и В.Н. Попов. В те годы Людвиг Дмитриевич много работал за границей, но его фундаментальным решением было остаться в России. Он отказался, в частности, от предложения возглавить Институт теоретической физики в университете Стоуни-Брук после ухода на пенсию его многолетнего директора нобелевского лауреата Ч.-Н. Янга. Его постоянной заботой было сохранение фундаментальной науки, су́дьбы Математического института и Отделения математических наук РАН.

В новых условиях возникли и новые интересные возможности сотрудничества. Выше уже упомянуты работы Л. Д. Фаддеева, выполненные совместно с А. Ниеми. Лагранжиан модели с заузленными солитонами удается получить с помощью некоторых замен переменных из фундаментального лагранжиана поля Янга-Миллса; есть надежда, что солитоны с нетривиальным инвариантом Хопфа соответствуют гипотетическим коллективным возбуждениям поля Янга-Миллса в квантовой хромодинамике. Еще один сюжет, связанный с полями Янга-Миллса, которым Л.Д. Фаддеев занимался вплоть до последних месяцев жизни, - это проблема возникновения массы. Людвиг Дмитриевич всегда несколько скептически относился к стандартному в настоящее время способу введения массы в теорию Янга-Миллса - с помощью так называемого "механизма Хиггса"; он хотел связать ее с правильным способом перенормировки, в результате которой в теории, не содержащей первоначально никаких размерных параметров, возникает размерная константа, задающая масштаб масс. Л. Д. Фаддеев несколько раз возвращался к этому сюжету. Описанию сценария перенормировки поля Янга-Миллса посвящена и его последняя работа, написанная вместе с С.Э. Деркачевым и последним студентом-дипломником Людвига Дмитриевича А. В. Ивановым.

Другой важнейшей темой в 1990-е и 2000-е годы оставался квантовый метод обратной задачи. Одним из его неожиданных применений стала физика высоких энергий - как хорошо известно еще с 1960-х годов, при больших переданных импульсах релятивистские амплитуды рассеяния становятся эффективно двумерными, и это 
позволило применить для их изучения методы, отработанные при изучении двумерных интегрируемых моделей. Этому вопросу были посвящены работы Л.Н. Липатова, Л. Д. Фаддеева и Г. П. Корчемского. Работа над более глубокими аспектами квантового метода обратной задачи привела к изучению бесконечномерных реализаций квантовых $R$-матриц и к важнейшей концепции модулярной двойственности для квантовых групп и алгебр Ли. Работа Л. Д. Фаддеева о модулярном дубле квантовой группы представляет собой глубокий "задел" для будущих исследований, связанных с нетривиальными новыми главами теории представлений, некоммутативной геометрией, теорией специальных функций ( $q$-дилогарифмы), квантовой гравитацией и множеством других сюжетов, изучение которых только начинается.

Еще одно нетривиальное применение квантового метода обратной задачи связано с изучением теорий Янга-Миллса. Когда-то, в первые годы развития теории интегрируемых систем, существовала романтическая надежда, что теория Янга-Миллса тоже окажется интегрируемой. Это неверно, но вариант теории - так называемая суперсимметричная теория Янга-Миллса - действительно близка к интегрируемости, или точной решаемости. Как недавно обнаружили Н. А. Некрасов и С. Л. Шаташвили, описание вакуумного сектора в суперсимметричной теории Янга-Миллса (в частности, в четырехмерном пространстве-времени) непосредственно приводит к квантовым интегрируемым системам. В этом новом подходе к суперсимметричным калибровочным теориям находят свое место все основные ингредиенты квантового метода обратной задачи. Активная работа в этой области продолжается и в настоящее время. Эта поражающая воображение связь между внешне далекими аспектами научного наследия Л. Д. Фаддеева - может быть, одно из лучших свидетельств его глубины.

Награды Л. Д. Фаддеева включают премию Д. Хайнемана в области математической физики (1974), медаль Дирака (1990), медаль им. Макса Планка (1996), премию им. И. Я. Померанчука (2002), премию А. Пуанкаре (2006), премию Шао (2008, совместно с В. И. Арнольдом), Государственную премию СССР (1971), Государственные премии Российской Федерации (1995, совместно с А. А. Славновым; 2005), Демидовскую премию (2002), медаль им. Л. Эйлера (2002) и медаль им. М. В. Ломоносова РАН (2013). В августе 2016 г. на 23-й международной конференции по квантовой теории нескольких частиц было объявлено об учреждении международной медали им. Л. Д. Фаддеева. Он был иностранным членом ряда академий и научных обществ, в том числе Парижской академии наук (с 2002 г.), Лондонского Королевского общества (с 2010 г.) и Национальной академии наук США (с 1990 г.).

Наследие Людвига Дмитриевича, его идеи остаются с нами и будут определять развитие математической и теоретической физики еще многие десятилетия.

И. Я. Арефъева, В.Е. Захаров, В.В. Козлов, И. М. Кричевер, В.П. Маслов, С. П. Новиков, А. М. Поляков, Н. Ю. Решетихин, М. А. Семенов-Тян-Шанский, Е. К. Склянин, Ф. А. Смирнов, Л. А. Тахтаджсян, С. Л. Шаташвили 